\title{
LITERATUR
}

\section{Maurice Guernier}

\section{Die Dritte Welt: drei Viertel der Welt}

Bericht an den Club of Rome, Piper, München und Zürich, 1981, 180 S., DM 26,-

Die eingangs gestellte Frage des Autors, ob es noch dieses weiteren Buches über die Probleme der Dritten Welt bedürfe, wird man nach der Lektüre mit einem schlichten Nein beantworten müssen. Es will weniger nüchterne Analyse liefern, sondern "wachrütteln". Dies gelingt aber auch nur sehr unvollkommen. Das hängt einmal mit der zu Ubertreibungen neigenden (der nukleare Holocaust verblasse gegenüber den Problemen der Dritten Welt, dort habe praktisch kein Fortschritt stattgefunden, der Graben werde immer tiefer etc.) und undifferenzierten Argumentation zusammen (es wird ständig von der Dritten Welt als ganzes geredet), zum anderen mit der sehr pauschalen Problemidentifikation. Als hauptsächliche Entwicklungshindernisse werden das Klima, die ungebremste Bevölkerungsvermehrung und die Kleinstaaterei angesehen, als Lösungsmodelle die traditionellen Rezepturen (Entwicklungshilfe, westliche/östliche Entwicklungsmodelle, internationale Konferenzen im Rahmen der Vereinten Nationen) kategorisch verworfen. Der Autor bietet stattdessen als Allheilmittel ein Aufgehen der angeblich nicht entwicklungsfähigen 115 Entwicklungsländer in fünf regionalen Gemeinschaften an, die sich nach dem Muster der Europäischen Gemeinschaft (vom Autor aus persönlichen Gründen stark idealisiert) bilden, intern Freihandel praktizieren sollen, nach außen aber nur über Staats- bzw. Gemeinschaftsverträge kooperieren sollen. Hier spiegelt sich denn auch noch die französische Vorliebe für den gelenkten Welthandel. Auf der lokalen Ebene wird für strikte Dezentralisierung plädiert, Modell stehen dabei die tansanischen Ujamaa-Dörfer. Weitere Hinweise auf interne Strukturreformen wird man vergeblich suchen. Zuletzt sollen die Entwicklungsländer auch nicht sklavisch die westlichen/östlichen Industrieländer kopieren, sondern gleich zum Sprung ins postindustrielle Zeitalter ansetzen. Wie dies geschehen soll, bleibt der Phantasie des Lesers überlassen.

Es ist müßig über den Realismus der Vorschläge des Autors zu rechten, der selbst überaus optimistisch ist, sich damit durchzusetzen, angebracht ist es aber zu fragen, ob der Sache der Dritten Welt mit solch aphoristisch dahingeschluderten Aufrüttelungstraktaten gedient ist, die nahezu ohne Empirie und Entwicklungstheorie auskommen. Bleibt nur noch anzumerken, daß auch die Übersetzung $z$. T. fehlerhaft ist.

Joachim Betz 